\title{
Pengaruh Social Media Advertising dan Event Marketing terhadap Brand Awareness dan Dampaknya pada Purchase Intention Produk Tenue de Attire
}

\author{
Rita Rita \\ Universitas Bina Nusantara \\ rita@binus.ac.id \\ Shania Febrine Nabilla \\ Universitas Bina Nusantara \\ Shaniafebrine97@gmail.com
}

\begin{abstract}
The purpose of this study was to determine the relationship and influence between Social Media Advertising and Event Marketing on Brand Awareness and its impact on Tenue de Attire's Purchase Intention products. The population in this study were people who follow the official Tenue de Attire account on Instagram. This study uses Path Analysis to measure the relationship and the influence of independent variables with dependent variables. In this study, data was obtained by collecting questionnaires to the population through Direct Message. The results obtained in this study are, Social Media Advertising and Event Marketing have a significant influence on Brand Awareness and its impact on Tenue de Attire's Purchase Intention products.
\end{abstract}

Keywords Social Media Advertising, Event Marketing, Brand Awareness, Purchase Intention

\section{PENDAHULUAN}

Industri garmen merupakan salah satu bentuk usaha yang memproduksi pakaian jadi dalam kuantiti yang besar. Saat ini industri tekstil dan garmen menjadi industri yang strategis bagi perekonomian di Indonesia. Hal ini dikarenakan Indonesia memiliki jumlah penduduk yang besar yaitu lebih dari 250juta jiwa dan juga sejalan dengan kebutuhan masyarakatnya akan pakaian. Industri ini juga merupakan salah satu industri yang mendongkrak pertumbuhan ekonomi indonesia. Saat ini juga, selain memenuhi kebutuhan pasar lokal sekarang ini juga sudah mencapai pasar internasional. Dan juga , industri garmen merrupakan industri yang menyerap banyak tenaga kerja.Disebutkan bahwa industry tekstil menyerap 1,3 juta tenaga kerja.

Industri tekstil dan produk tekstil (TPT) diprediksi kembali menggeliat karena pasar ekspor dan kebutuhan domestik tumbuh. Menteri Perdagangan Enggartiasto Lukita mengatakan pemerintah mengajak pengusaha tekstil dan produk tekstil untuk memenuhi kebutuhan domestik. Dia mengatakan kondisi usaha tekstil Indonesia kini tengah maju. Berbeda dengan tahun-tahun sebelumnya yang mengalami penurunan. 


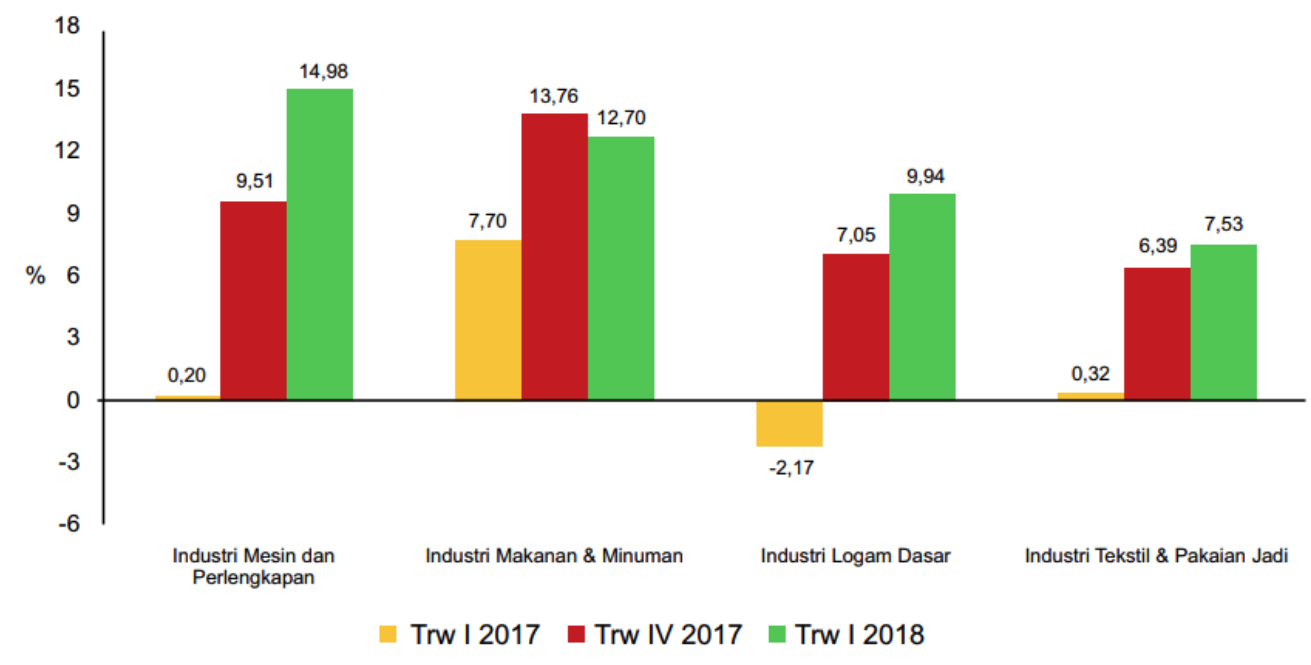

Gambar 1. Pertumbuhan Empat Kelompok Industri Yang Mengalami Pertumbuhan Tinggi Pada Triwulan I 2018

Sumber : Kementrian Perindustrian Republik Indonesia

Gambar 1 menjelaskan tentang pertumbuhan empat kelompok industry yang mengalami pertumbuhan tinggi pada triwulan I 2018 dalam bentuk persen dari tahun ketahun. Dapat dilihat, pertumbuhan industri tekstil dan pakaian jadi mengalami kenaikan . Mulai dari Triwulan I 2017 yaitu sebesar 0,32\% naik menjadi 6,39\% pada Triwulan IV 2017 dan naik menjadi 7,53\% pada Triwulan I 2018. Bagusnya pertumbuhan tekstil dan pakaian jadi di Indonesia merupakan dampak dari indsutri fashion yang juga berkembang pesat di Indonesia. Pada tahun 2017, Industri fashion di Indonesia telah menyumbang kontribusi terhadap Pendapatan Domestik Bruto (PDB) nasional sebesar 3,76 \%. Dalam perkembangan awalnya, sejarah fashion di Indonesia cenderung meniru gaya barat baik itu dalam bahan yang digunakan maupun dalam desain. (Kementrian Perindustrian Republik Indonesia:2018)

Saat ini industry fashion mengalami perkembangan yang sangat pesat. Menurut Triawan Munaf selaku Kepada Badan Ekonomi Kreatif Indonesia, untuk ekonomi kreatif, fashion merupakan penyumbang kedua terbesar PDB setelah kuliner. Hal ini dapat dilihat dari banyaknya produk-produk fashion yang berkualitas dan inovatif , baik brand luar negeri ataupun dalam negeri. (Triawan Munaf, Kominfo.go.id :2017). Secara umum fashion bisa diartikan sangat beragam, karena meliputi seni, bahasa, arsitektur dan juga masakan. Meskipun dalam kesehariannya, istilah ini lebih sering ditujukan untuk menyebutkan gaya berpakaian atau busana. Sedangkan menurut ahli Polhemus dan Procter, kalangan masyarakat di dunia barat menyebutkan fashion sebagai istilah untuk menunjukan gaya, busana serta dandanan. Oleh sebab itu, tidak mengherankan apabila kemudian pada perkembanganya makna fashion hanya dianggap sebagai suatu trend busana dan gaya. 


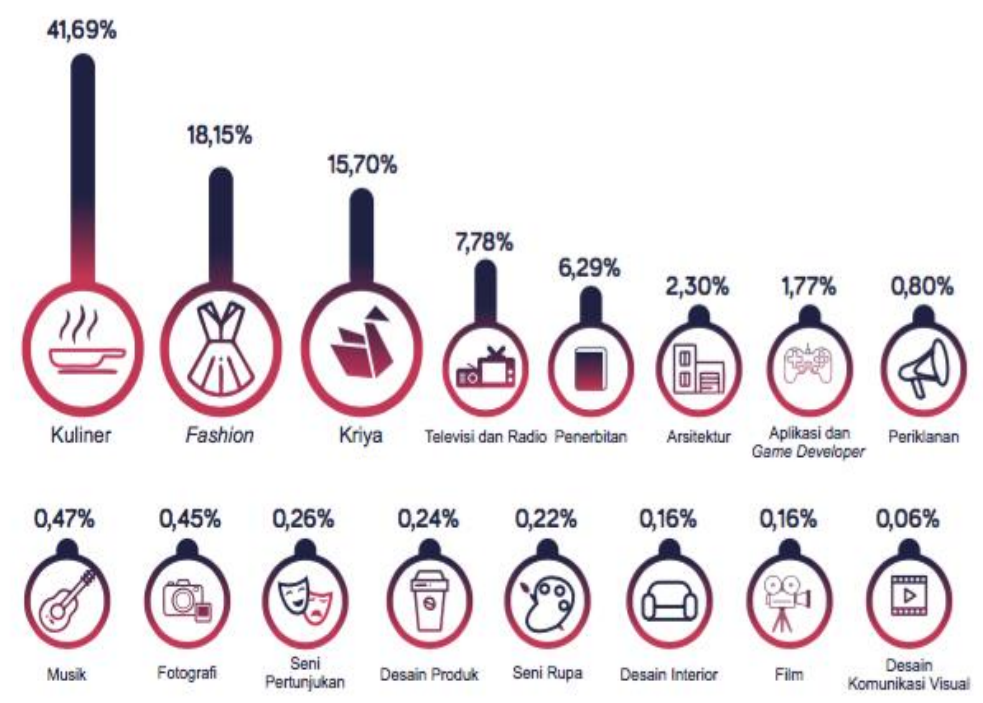

Gambar 2 Katerogori pertumbuhan produk paling pesat

Sumber : Badan Ekonomi Kreatif dan Badan Pusat Statistik Indonesia Maret 2017

Gambar 2. merupakan hasil survey kategori produk dengan pertumbuhan paling pesat saat ini. Kuliner, fashion, kriya, televise dan radio, dan penerbitan menduduki posisi lima teratas. Diposisi pertama diduduki oleh kuliner dengan 41,69\%, disusul oleh fashion $18,15 \%$, yang ketinga diduduki oleh kriya sebesar $15,7 \%$, lalu pada posisi keempat adalah televisi dan radio sebesar 7,78\% dan posisi kelima yaitu penerbitan sebesar 6,29\%. Triawan Munaf kembali menambahkan bahwa, pemilik label lokal yang didominasi oleh generasi muda merupakan salah satu mengapa industry fashion menjadi penyumbang PDB kedua terbesar. Saat ini minat generasi muda untuk membangun sendiri merek mereka juga sangat besar. "Saya yakin, paduan talenta yang melimpah dan keberagaman buda Nusantara menjad kekuatan luar biasa yang akan mendorong pertumbhan sektor ini” Triawan Munaf. Industri clothing brand lokal mulai tumbuh sejak pertengahan tahun 90an. Bandung disebut sebagai tempat awal berkembangnya distro yang kemudian berkembanga menjadi ikon fashion anak muda masa kini. Selanjutnya, distro menyebar ke berbagai kota di Indonesia. Local clothing brand dicirikan dengan desain yang kreatif dan jumlah produksi yang terbatas. Biasanya, produk atau desain yang sudah terjual habis, tidak akan diproduksi kembali. (Triawan Munaf, Retas : 2017)

Salah satu pelaku industri fashion kreatif adalah Tenue de Attire. Tenue de Attire sendiri merupakan clothing brand lokal. Brand lokal di bawah PT Iris Tri Drata ini sudah berdiri sejak tahun 2013. Tenue de Attire memiliki tagline yaitu Passionate Shirtmaker . Produk yang ditawarkan oleh brand ini mayoritas adalah kemeja . Namun selain kemeja, brand ini juga menawarkan jaket dan celana. Dapat dilihat, desain pattern atau motif brand ini unik memiliki ciri khas tersendiri. Hal ini karena mereka mendesain motifnya sendiri,sehingga tidak dimiliki oleh brand lain. Tenue de Attire juga beberapa kali bekerja sama dengan beberapa pihak untuk membuat collab version design. Contohnya, desain yang dinamai “L'INDÉPENDANCE INDONÉSIENNE", yaitu kolaborasi antara Tenue de Attire x Harimerdeka. Selain itu , juga ada “ JOUIR COLLECTION” yaitu kolaborasi antara Tenue de Attire x Elephant Kind. 


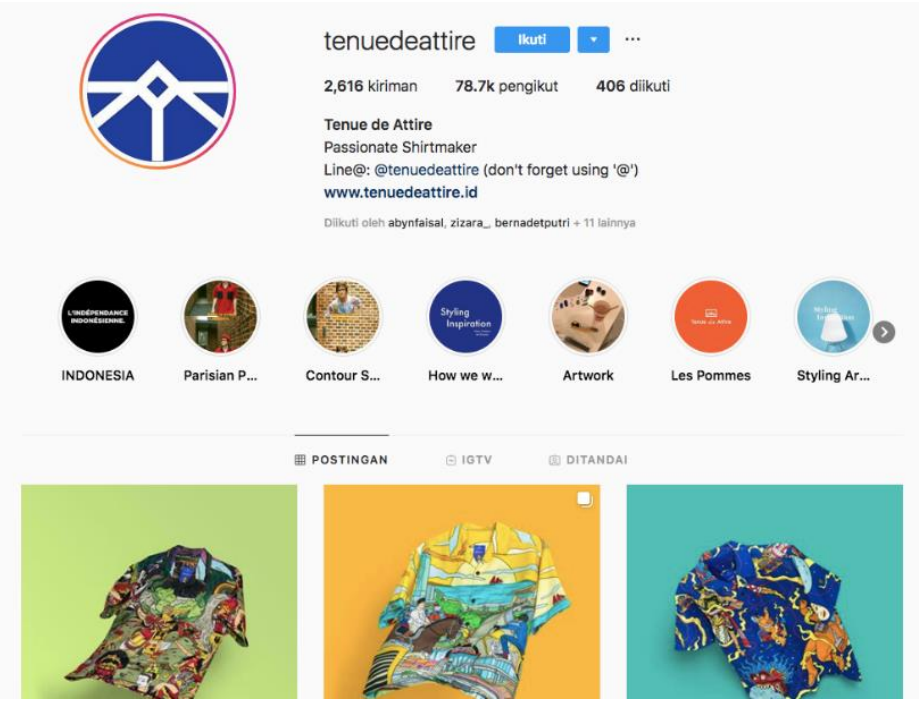

Gambar 3. Instagram Resmi Tenue de Attire

Sumber: Instagram,2019

Gambar 3. merupakan akun media sosial instagram resmi milik Tenue de Attire. Dapat dilihat Tenue de Attire sudah memiliki lebih dari 78 ribu pengikut. Banyaknya clothing brand lokal saat ini membuat persaingan antar merek sangatlah ketat. Mulai dari brand yang sudah sangat lama hingga yang baru. Hal itu juga membuat konsumen dihadapkan oleh banyak clothing brand lokal yang dapat mereka pilih. Hal ini tentu berdampak pada penjualan Tenue de Attire.

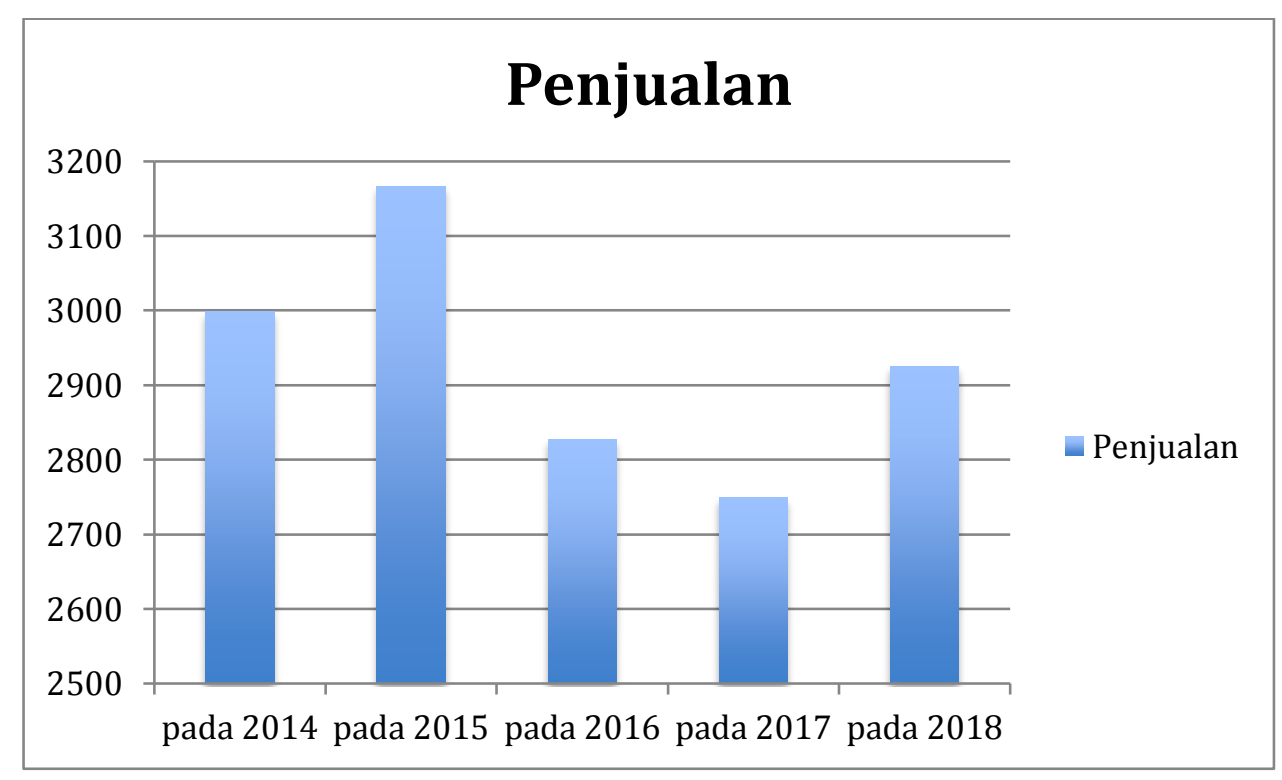

Gambar 4. Data Penjualan Tenue de Attire 2014 - 2018 (Dalam Kuantiti)

Sumber: Tenue de Attire, 2019

Dari data pada gambar 4, selama lima tahun terakhir Tenue de Attire masih pengalami fluktuasi . Pada tahun 2014 penjualan tenue de attire sebanyak 2999 pcs, lalu pada tahun 2015 mengalami peningkatan menjadi 3167 pcs. Pada tahun 2016 mengalami penurunan menjadi 2827 pcs, lalu mengalami penurunan lagi pada tahun 2017 menjadi 2749 pcs dan 


\section{JESYA}

JURNAL EKONOMI \& EKONOMI SYARIAH

Jurnal Ekonomi \& Ekonomi Syariah Vol 5 No 1, Januari 2022

E-ISSN : 2599-3410 | P-ISSN : 2614-3259

DOI : https://doi.org/10.36778/jesya.v5i1.606

mengalami sedikit kenaikan menjadi 2925 pcs pada tahun 2018. Renaldi selaku CEO Tenue de Attire juga menambahkan bahwa cara Tenue de Attire berpromosi adalah melalui iklan media sosial dengan cara beriklan diInstagram nanti postingan yang dipilih untuk jadi iklan akan muncul di Story atau di Home instagram orang-orang yang sudah disetting untuk dijadikan target. Lalu Tenue de Attire juga berpartisipasi dengan menjdai tenan di PopUpMarket. Menurut penelitian yang dilakukan We Are Social, perusahaan media asal Inggris yang bekerja sama dengan Hootsuite, rata-rata orang Indonesia menghabiskan tiga jam 23 menit sehari untuk mengakses media sosial. Indonesia menduduki peringkat ketiga negara yang paling sering menggunakan media social, yaitu dengan rata-rata 3 jam 23 menit dalam seharinya. Posisi pertama diduduki oleh Filipina dengan rata-rata 3 jam 57 menit lalu disusul oleh Brazil sebagai peringkat kedua dengan rata-rata 3 jam 39 menit. Berdasarkan aplikasi yang paling banyak diunduh, perusahaan media sosial di bawah Mark Zuckerberg mendominasi di tiga teratas. Secara berurutan dari posisi pertama adalah WhatsApp, Facebook, Instagram, dan baru diikuti media sosial buatan Korea Selatan, Line.

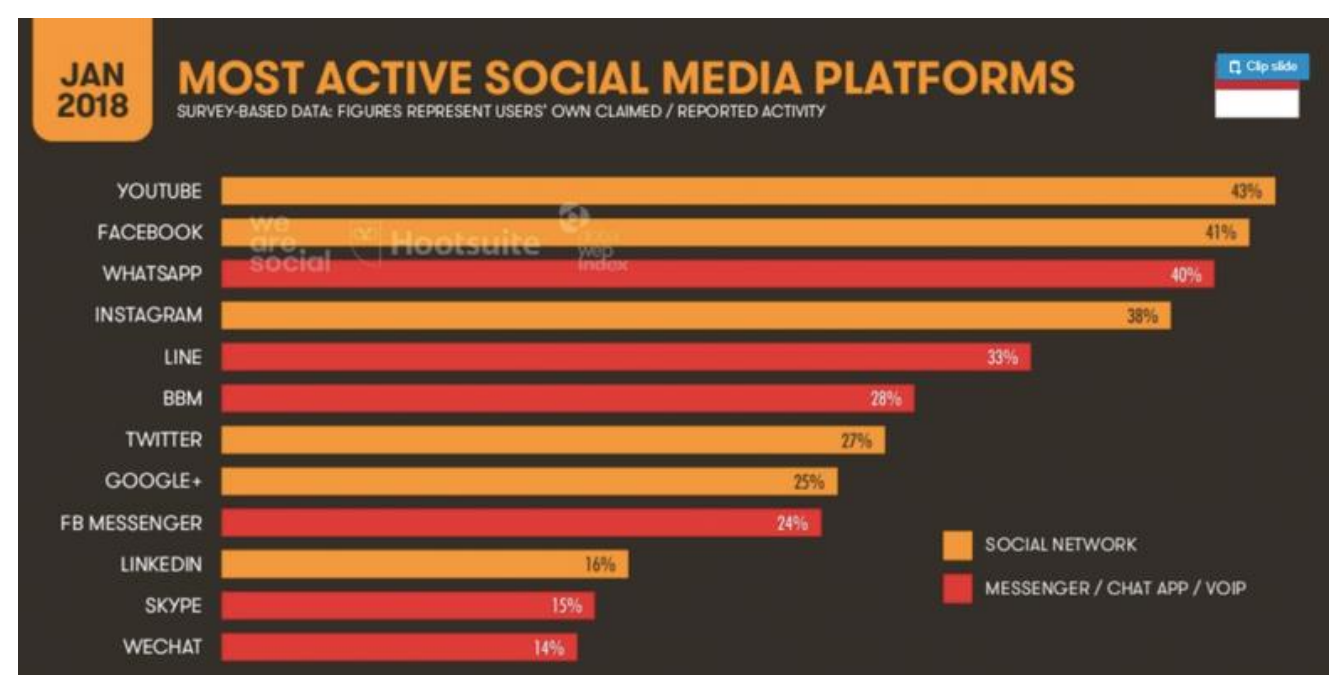

Gambar 5. Most Active Social Media Platforms

Sumber: We are Social dan Hootsuite

Gambar 5, merupakan hasil survey tentang social media platform yang paling aktif digunakan masyarakat Indonesia pada bulan Januari 2018. Peringkat pertama diduduki oleh Youtube 43\%, lalu disusul oleh Facebook 41\%, whatsapp 40\%, Instagram 38\% dan diposisi kelima diduduki oleh Line 33\%. Tingginya penggunaan media sosial membuat media sosial menjadi salah satu platform iklan terbaru dan menjadi media yang sangat efektif untuk beriklan saat ini . Pada jurnal internasional Impact of Advertising on Brand Awareness and Commitment in Female Apparel Industry (Khan, Jadoon, \& Tareen, 2016) menyebutkan bahwa media sosial saat ini menjadi media beriklan yang paling di perhatikan oleh para marketers. Social media advertising itu sendiri adalah media beriklan yang memanfaatkan internet atau juga disebut sebagai online advertising (Misra \& Vashisth, 2017). Social media advertising memiliki pengaruh terhadap niat beli konsumen (Dao, Le, Cheng, \& Che, 2014). 


\section{LANDASAN TEORI \\ Social Media Advertising}

Menurut Ertemel dan Ammoura (2016) social media advertising dapat dianggap sebagai Iklan online yang menggabungkan interaksi pengguna yang telah disetujui konsumen untuk ditampilkan dan dibagikan. Iklan yang dihasilkan menampilkan interaksi ini bersama dengan orang orang pengguna (gambar dan / atau nama) dalam konten Iklan. Menurut Misra and Vashisth (2017) menyatakan bahwa social media advertising meruapakan internet advertising yang menggunakan media sosial sebagai medianya .Dari kedua pengertian tersebut, peneliti menyimpulkan bahwa iklan media sosial merupakan kegiatan promosi secara online dan menggunakan media sosial sebagai media beriklannya

\section{Event Marketing}

Menurut Kennedy (2009) menjelaskan bahwa, Event, suatu kurun waktu kegiatan yang dilakukan oleh perusahaan dengan mendatangkan orang-orang ke suatu tempat agar mereka memperoleh informasi atau pengalaman penting serta tujuan lain yang diharapkan oleh penyelenggara. Definisi event marketing buku Nigel Jackson (2013) adalah perkumpulan banyak orang pada waktu dan tempat tertentu untuk tujuan merayakan, berkomunikasi, mengedukasi, reuni. Dari kedua pengertian tersebut, peneliti menyimpulkan bahwa event marketing adalah sebuah kegiatan di mana perusahaan mengikuti acara baik besar ataupun kecil untuk keperluan mempromosikan produknya ke masyarakat

\section{Brand Awareness}

Pengertian Brand Awareness Menurut Aaker, dalam Wu \& Ho, (2014), Brand Awareness adalah kemampuan pasar atau konsumen untuk mengenali, mengidentifikasi dan menghafal ataupun mengingat sebuah merek dalam katerogi produk tertentu. Chiu, Kevin Kuan-Shun, Ru-Jen Lin, Maxwell K Hsu, Li-Hua Huang (2010) mendefinisikan Brand Awareness sebagai tingkat dasar pengetahuan merek yang melibatkan pengakuan merek dan dapat di anggap sebagai kemampuan konsumen untuk mengenali sebuah merek dalam suatu kelompok produk atau jasa dalam rincian yang memadai untuk melakukan pembelian. Dari kedua pengertian tersebut, peneliti menyimpulkan adalah Brand Awareness adalah kemampuan konsumen untuk mengenali merek suatu produk atau menyadari ketika disebutkan ciri-ciri dari merek tersebut.

\section{Purchase Intention}

Irshad (2012) mendefinisikan purchase intention sebagai niat beli yang mengacu pada kesediaan pelanggan untuk membeli merek, peningkatan dan melanjutkan penggunaannya. Menurut Kotler \& Armstrong (2012), purchase intention konsumen berkaitan erat dengan perilaku konsumen. Hal tersebut terjadi ketika konsumen mendapatkan stimulasi dari faktor-faktor eksternal yang pada akhirnya memunculkan niat untuk membeli yang didasarkan pada karakteristik setiap individu. Faktor faktor tersebut dapat dikategorikan seperti merek, produk, retailer, waktu pembelian dan kuantitas pembelian. Dari kedua pengertian tersebut, peneliti menyimpulkan purchase intention adalah kegiatan seseorang yang secara langsung terlibat dalam mendapatkan sebuah produk yang menciptakan motivasi. Jika minat terhadap produk tersebut tinggi maka mendorong seseorang untuk membeli produk tersebut. 


\section{Pengembangan Hipotesis}

\section{Hubungan Social Media Advertising terhadap Brand Awareness}

Salah satu meningkatkan kesadaran konsumen akan sebuah merek adalah dengan malakukan kegiatan beriklan. Salah satu media beriklan yang efektif saat ini adalah dengan menggunakan media sosial. Seperti pada jurnal "Impact of Advertising on Brand Awareness and Commitment in Female Apparel Industry" yang menyatakan bahwa Brand Awareness adalah hasil dari iklan yang mengingatkan pelanggan akan sebuah merek saat melakukan pembelian . (Khan, Jadoon, \& Tareen, 2016). Berdasarkan uraian penelitian tersebut, maka dikemukakan hipotesis sebagai berikut:

H1 : Social Media Advertising berpengaruh terhadap Brand Awareness

\section{Hubungan Event Marketing terhadap brand awareness}

Salah satu meningkatkan brand awarensss adalah dengan mengajak customer untuk terlibat dalam sebuah kegiatan event yang diselenggaran oleh perusahaan. Seperti yang di jelaskan pada jurnal "The impact of event marketing on brand equity " yang menyatakan bahwa event marketing tidak hanya berkontribusi dalam peningkatan salah satu dari komponen brand equity saja. tetapi juga berpengaruh terhadap seluruh komponen komponen brand equity. Pada jurnal ini brand equity memiliki lima komponen yaitu, Lima komponen dari brand equity: Brand Awareness, brand associa- tions, perceived quality,brand loyalty, dan aset eksklusif lainnya seperti paten, merek dagang, dan hubungan saluran (Zarantonello \& Schmitt, 2013). Berdasarkan uraian penelitian tersebut, maka dikemukakan hipotesis sebagai berikut:

$\mathrm{H} 2$ : Event Marketing berpengaruh terhadap brand awareness.

\section{Hubungan Social Media Advertising terhadap Purchase intention}

Strategi beriklan digunakan untuk menawarkan produk agar menarik minat konsumen . Dengan adanya iklan,konsumen dapat mengetahui detail atau informasi mengenai produk yang akan ia beli. Semakin baik sebuah iklan, akan perpengaruh positif terhadap minat beli konsumen. Hal ini dijelaskan pada jurnal yang berjudul "Social media advertising value :The case of transitional economies in Southeast Asia" yang menyatakan bahwa social media advertising memiliki efek positif terhadap consumer's perceived value yang mana akan berpengaruh secara positif terhadap purchase intention. (Dao, Le, Cheng, \& Che, 2014). Berdasarkan uraian penelitian tersebut, maka dikemukakan hipotesis sebagai berikut:

H3 : Social media advertising berpengaruh terhadap purchase intention

\section{Hubungan Event Marketing terhadap Purchase Intention}

Salah satu cara berpromosi untuk meningkatkan purchase intention konsumen adalah dengan cara event marketing, hal ini karena pada event marketing konsumen tidak hanya sekedar hanya melihat produk yang ditawarkan, tetapi juga dapat melihat, menyentuh dan mencoba langsung produk yang ditawarkan. Menurut jurnal "Pengaruh Event Marketing Cornetto Summer Music Festival 2012 Terhadap Minat beli Cornetto" menyatakan bahwa Event Marketing memiliki pengaruh yang tinggi terhadap purchase intention konsumen. (Saronto \& Rosinta, 2013). Berdasarkan uraian penelitian tersebut, maka dikemukakan hipotesis sebagai berikut:

H4 : Event Marketing berpengaruh terhadap purchase intention 


\section{Hubungan Brand Awareness terhadap Purchase Intention}

Kesadaran terhadap sebuah merek mempengaruhi purchase intention terhadap produk dari merek tersebut . Ini diperjelas dalam jurnal "Effect of Consumer-Based Brand Equity on Purchase Intention: Considering Socioeconomic Status and Gender as Moderating Effects " yang menyatakan bahwa Brand Awareness merupakan faktor yang memberikan efek terbesar pada peningkatan purchase intention (Aydın \& Ulengin, 2015). Berdasarkan uraian penelitian tersebut, maka dikemukakan hipotesis sebagai berikut:

H5 : Brand Awareness berpengaruh terhadap purchase intention

\section{III.METODOLOGI PENELITIAN}

Pada penelitian ini, peneliti menggunakan metode penelitian kuantitatif dengan jenis asosiatif. Horizon waktu yang digunakan pada penelitian ini adalah cross sectional. Cross sectional adalah jenis penelitian yang pengumpulan datanya hanya dikumpulkan sekali dan biasanya periode penelitiannya hanya dalam beberapa hari atau minggu ataupun bulan. Dalam penelitian ini, peneliti menggunakan dua sumber data, yaitu data primer dan data sekunder. Data primer ini didapatkan dengan cara menyebarkan kuisioner kepada followers instagram Tenue de Attire. Dalam kuisioner tersebut sudah disiapkan pilihan jawaban, sehingga responden tinggal memilih jawaban yang sesuai dengan apa yang mereka rasakan atau alami. Dalam penelitian ini penulis menggunakan probability sampling sebagai teknik dalam pengambilan sampel. Dan peneliti menggunakan simple random sampling, yaitu pengambilan sampel secara acak tanpa memperhatikan strata yang ada pada populasi. Populasi penelitian adalah followers instagram Tenue de Attire dan selanjutnya teknik pengambilan sampel menggunakan rumus Slovin didapat 100 responden. Adapun Analisa data menggunakan program SPSS

\section{HASIL DAN PEMBAHASAN}

Hasil Analisis Jalur (Path Analysis)

\begin{tabular}{|c|c|c|c|c|}
\hline \multirow{2}{*}{$\begin{array}{l}\text { Pengaruh } \\
\text { Variable }\end{array}$} & \multicolumn{2}{|c|}{ Pengaruh Kausal } & \multirow{2}{*}{$\begin{array}{l}\text { Sisa } \\
\varepsilon 1 \text { dan } \varepsilon 2\end{array}$} & \multirow[t]{2}{*}{ Total } \\
\hline & Langsung & Melalui Y & & \\
\hline X1 terhadap Y & 0.391 & & & 0.391 \\
\hline X2 terhadap Y & 0.426 & & & 0.426 \\
\hline $\begin{array}{l}\text { X1,X2 terhadap } \\
\text { Y }\end{array}$ & 0.502 & & 0.498 & 1 \\
\hline \multirow[t]{2}{*}{$\mathrm{X} 1$ terhadap $\mathrm{Z}$} & 0.195 & & & 0.195 \\
\hline & 0.195 & $\begin{array}{l}=0.319 \times 0.410 \\
=0.130\end{array}$ & & 0.325 \\
\hline \multirow[t]{2}{*}{$\mathrm{X} 2$ terhadap $\mathrm{Z}$} & 0.328 & & & 0.328 \\
\hline & 0.328 & $\begin{array}{l}=0.426 \times 410) \\
=0.175\end{array}$ & & 0.502 \\
\hline Y terhadap $\mathrm{Z}$ & 0.410 & & & 0.410 \\
\hline $\begin{array}{l}\mathrm{X} 1, \mathrm{X} 2, \mathrm{Y} \\
\text { terhadap Z }\end{array}$ & 0.642 & & 0.358 & 1 \\
\hline$\varepsilon 1$ & 0.706 & & & 0.706 \\
\hline$\varepsilon 2$ & 0.598 & & & 0.598 \\
\hline
\end{tabular}

Sumber: Olah Data SPSS

analisis jalur atau Path analyisis dapat digambarkan sebagai berikut: 


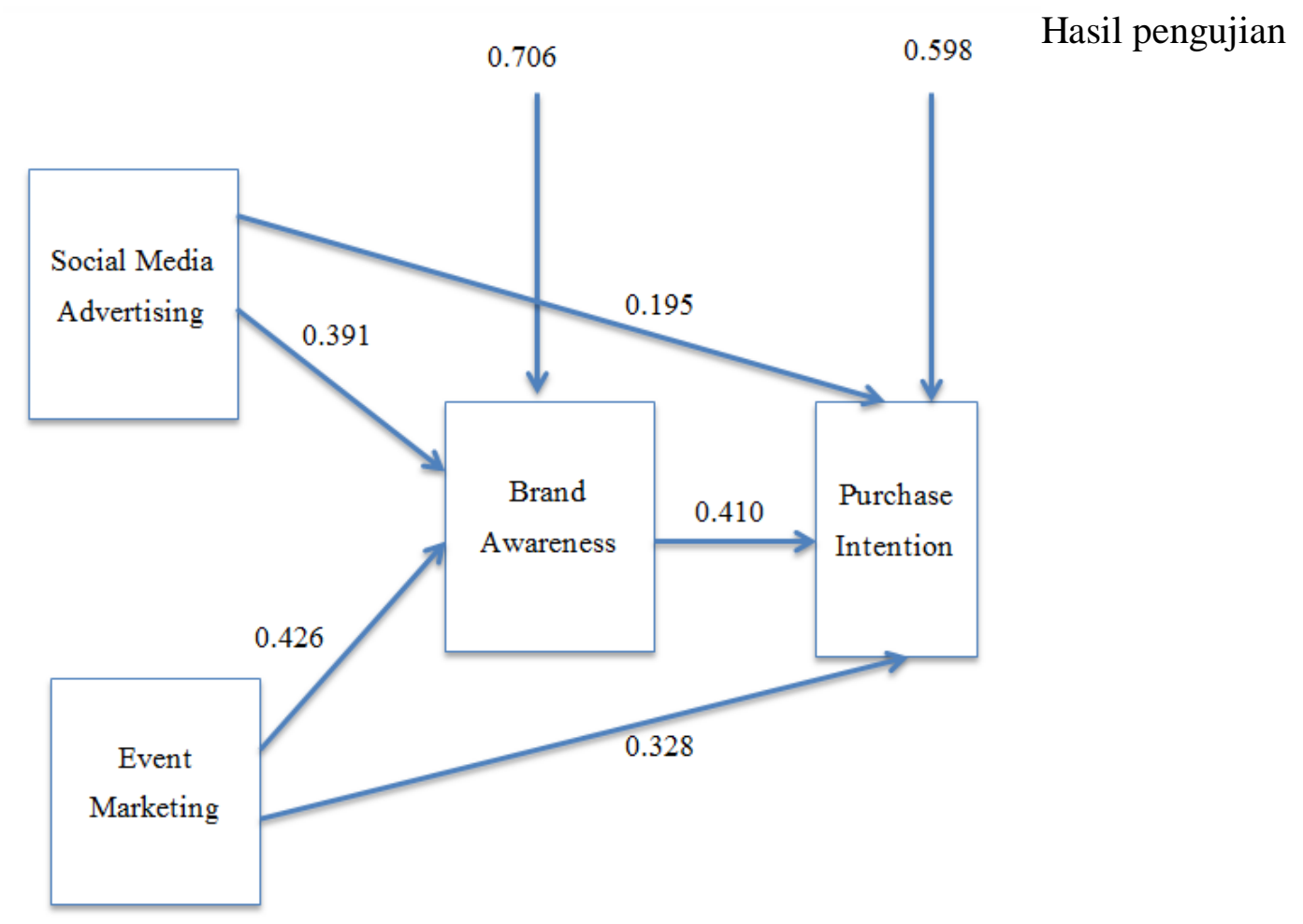

Gambar 6. Hasil Pengujian Analisis Jalur Keseluruhan

Sumber: Olah Data SPSS

\section{Pembahasan}

Berdasarkan hasil pengolahan data, rata-rata indikator terendah pada variabel social media advertising adalah indikator 1 dengan nilai 2.66 , yang berbunyi "Saya merasa iklan merek Tenue deAttire yang ditampilkan di media sosial merupakan sumber informasi yang penting mengenai produknya". Oleh karena itu penulis menyarakan kepada Tenue de Attire untuk memberikan informasi yang lebih informatif untuk ditampilkan pada iklan. Tenue de Attire bisa menambahkan informasi penting, seperti menambahkan nama koleksi desain tersebut, informasi detail produk, informasi masa / periode promo berlangsung, informasi mengenai value apa saja yang didapat jika memesan produk hari ini (seperti promo gratis ongkos pengiriman atau potongan harga tambahan khusus hari ini)

Berdasarkan hasil pengolahan data, rata-rata indikator terendah pada variabel event marketing adalah indikator 5 dengan nilai 2.63, yang berbunyi "Saya merasa Tenue de Attire memberikan manfaat yang berarti" . Tenue de Attire memiliki desian motif yang unik dan berbeda dengan brand lain. Oleh karena itu penulis menyarakan saat event berlangsung Tenue de Attire memberikan workshop singkat atau memberikan penjelasan singkat kepada orang-orang yang datang mengenai keunikan design yang dimiliki Tenue de Attire. Seperti contohnya pada koleksi L'INDÉPENDANCE INDONÉSIENNE yang bertemakan PEMILU. Saat event berlangsung, Tenue de Attire bisa memberikan penjelasan atau informasi menarik mengenai keunikan koleksi tersebut. Alasan mengapa mengeluarkan koleksi yang bertema PEMILU . Contoh lainnya adalah seri dari koleksi The Contour, yang dimana pada koleksi tersebut desainnya adalah berbentuk wajah- 
wajah manusia. Saat event tersebut Tenue de Attire bisa memberikan penjelasan mengenai makna dibalik desain tersebut.

Berdasarkan hasil pengolahan data, rata-rata indikator terendah pada variabel brand awareness adalah indikator 1 dengan nila 2.52, yang berbunyi "Brand Tenue de Attire adalah merek yang pertama kali terlintas dibenak saya". Oleh karena itu penulis menyarankan Tenue de Attire memasang iklan di Home atau Story Instagram menarik. masukan penawaran yang sulit ditolak konsumen,seperti potongan harga, penawaran gratis ongkos pengiriman, tambahan potongan harga khusus hari ini, penawaran khusus jika memberli dalam jumlah tertentu, dan ukuran tulisan penawaran (\%) dibuat dalam ukuran besar karena orang akan jauh lebih terarik untuk mengetahui iklan tersebut ketika mereka melihat adanya potongan harga. Selain itu, frekuensi tayang iklan juga ditambah, untuk saat ini frekuensi iklan Tenue de Attire masih sedikit. karena semakin sering target konsumen melihat iklan Tenue de Attire muncul di Home atau Story Instagram mereke, konsumen akan lebih cepat mengingat dan melekat dibenak konsumen.

Berdasarkan hasil pengolahan data, rata-rata indikator terendah pada variabel purchase intention adalah indikator 3 dengan nilai 2.60 "Saya akan membeli produk Tenue de Attire". oleh karena itu penulis menyarankan agar Tenue de Attire lebih aktif dalam melakukan promosi baik dengan memasang iklan yang lebih menarik dan bisa menambah frekuensi menjadi tenan di sebuah event, karena selama ini Tenue de Attire baru dua kali berpartisipasi menjadi tenan di PopUpMarket. Waktu atau musim terbaik untuk berpartisipasi menjadi tenan di sebuah bazar atau event adalah saat menjelang Natal dan Tahun baru, menjelang Ramadhan, Saat Ramadhan, menjelang lebaran, saat musim libur, saat Chinese New Year. Beberapa event fashion yang sesuai dengan karakteristik produk Tenue de Attire adalah PopUp Market, JakCloth, Indie Clothing Expo, Kickfest, Clothfest, PICA Fest, Bogor Clothing Fest.

\section{KESIMPULAN}

Berdasarkan hasil penelitian yang telah dilakukan, maka dapat disimpulkan beberapa hal , yaitu Social media advertising dan event marketing memiliki pengaruh terhadap brand awareness secara simultan. Pengaruhnya yaitu sebesar 0.502. Social media advertsing memiliki pengaruh secara parsial terhadap brand awareness sebesar 0.391. Event marketing memiliki pengaruh secara parsial terhadap brand awareness sebesar 0.426. Social media advertising dan event marketing memiliki pengaruh terhadap purchase Intention melalui brand awareness Pengaruhnya sebesar 0.642. Social media advertising memiliki pengaruh secara parsial terhadap purchase intention sebesar 0.130. Event marketing memiliki pengaruh secara parsial terhadap purchase intention sebesar 0.175

\section{DAFTAR PUSTAKA}

Aydın, G., \& Ulengin, B. (2015). Effect of Consumer-Based Brand Equity on Purchase Intention: Considering Socioeconomic Status and Gender as Moderating Effects . Journal of Euromarketing, 107-119.

Belch, G. E., \& Belch, M. A. (2009). Advertising and Promotion : An Integrated Marketing Communication Perspective. McGraw-Hill Irwin.

Chiu, Kuan-Shu, K., Lin, R.-J., Hsu, M. K., \& Huang, L.-H. (2010). Power of Branding On Internet Service Providers (Vol. 50). The Journal of Computer Information Systems. 
Dao, W. V.-T., Le, A. N., Cheng, J. M.-S., \& Che, D. C. (2014). Social media advertising value The case of transitional economies in Southeast Asia . nternational Journal of Advertising .

Elliot, Rundle-thiele, \& Waller. (2014). Marketing. Australia.

Ertemel, A. V., \& Ammoura, A. (2016). THE ROLE OF SOCIAL MEDIA ADVERTISING IN CONSUMER BUYING BEHAVIOR . Turkey: international Journal of Commerce and Finance .

Irshad. (2012). Service Based Brand Equity, Measure of Purchase Intention, Mediating Role of Brand Performance. Academy of Contemporary Research Journal.

Ismail, F. (2018). Statistika Untuk Penelitian Pendidikan dan Ilmu Ilmu Sosial. Indonesia: Prenadamedia Group.

Išoraite, M. (2016, April-June). RAISING BRAND AWARENEES THROUGH THE INTERNET MARKETING TOOLS. INDEPENDENT JOURNAL OF MANAGEMENT \& PRODUCTION , 7.

Jackson, N. (2013). Promoting and Marketing Events: Theory and Pratice. New York: Routleadge.

Karam, A. A., \& Saydam, S. (2015). An Analysis Study of Improving Brand Awareness and Its Impact on Consumer Behavior Via Media in North Cyprus (A Case Study of Fast Food Restaurants) (Vol. 6). Cyprus: International Journal of Business and Social Science .

Karam, A. A., \& Saydam, S. (2015, January ). An Analysis Study of Improving Brand Awareness and Its Impact on Consumer Behavior Via Media in North Cyprus (A Case Study of Fast Food Restaurants). International Journal of Business and Social Science, 6, 66 - 81.

Khan, A. A., Jadoon, S., \& Tareen, N. A. (2016). Impact of Advertising on Brand Awareness and Commitment in Female Apparel Industry (Vol. 6). Pakistan : International Journal of Academic in Business and Social Sciences.

Kotler, P., \& Amstrong, G. (2012). Principles of Marketing. New Jersey: Pearson.

Kotler, P., \& Amstrong, G. (2012). Principles Of Marketing. Pearson.

Kuncoro, E. A., \& Riduwan. (2008). Cara Menggunakan dan Memaknai Analisis Jalur. Bandung: Alfabeta.

Madhalena, E., \& Syahputra. (2016). PENGARUH EVENT MARKETING TERHADAP BRAND IMAGE ROKOK DJARUM SUPER MILD PT DJARUM (Vol. IV). Ecodemica .

Malik, M. E., Ghafoor, M. M., \& Iqbal, H. K. (2013). Importance of Brand Awareness and Brand Loyalty in assessing Purchase Intentions of Consumer . International Journal of Business and Social Science , 4(May).

McDaniel, C., Lamb, C., \& J.F.Hair. (2013). Introduction to Marketing 12th Edition. United States: Cengage Learning.

Misra, V., \& Vashisth, A. (2017). Is Advertising Medium an Important Constraint in Consumer Purchase Intention: e eoretical Foundation. Journal of General Management Research, 4, 38 - 45.

Nisfiannoor, M. (2009). Pendekatan Statistika Modern: Untuk Ilmu Sosial . (A. N. Dini, Ed.) Salemba Humanka.

Purnomo, R. A. (2017). Analisis Statistik Ekonomi dan Bisnis Dengan SPSS. CV.WADE GROUP. 
S, H. C. (2015). Influence of Social Media Advertising on Consumers Purchase Intention. INTERNATIONAL JOURNAL OF CURRENT ENGINEERING AND SCIENTIFIC RESEARCH (IJCESR), 2.

Sanusi, A. (2011). Metodologi Penelitian Bisnis. Jakarta: Salemba Empat.

Sari, D., \& Kusuma, B. (2014, June). Does Luxury Brand Perception Matter In Purchase Intention? A Comparison Between A Japanese Brand And A German Bran. ASEAN MARKETING JOURNAL, VI, 50 - 63.

Sarjono, H., \& Julianita, W. (2011). SPSS vs LISREL. Jakarta: Salemba Empat.

Saronto, A. A., \& Rosinta, F. (2013). PENGARUH EVENT MARKETING CORNETTO SUMMER MUSIC FESTIVAL 2012 TERHADAP MINAT BELI CORNETTO .

Sekaran, U., \& Bougie, R. (2013). Research Methods for Business: A Skill Building Approach. New York: John Wiley@Sons.

Shahid, Z., Hussain, T., \& aZafar, F. (2017). The Impact of Brand Awareness on The consumers' Purchase Intention. 33, 34-38. 